\title{
Quatro olhares sobre Pulsão: um diálogo sobre a pertinência e os limites do teatro relacional performativo
}

\section{Four perspectives about Pulsão: a dialogue on the relevance and limits of relational performative theater}

\author{
Beth Néspoli ${ }^{1}$ \\ Carminda Mendes André ${ }^{2}$ \\ Julio Groppa Aquino ${ }^{3}$ \\ Marcos Bulhões Martins ${ }^{4}$
}

\begin{abstract}
Resumo
Diálogo travado entre o diretor do espetáculo Pulsão, produzido pelo Desvio Coletivo, e três pesquisadores convidados para o dossiê da Revista Sala Preta. A abordagem metodológica de criação deste trabalho serviu de ponto de partida para considerações sobre a natureza e o sentido do fazer teatral hoje, destacando-se as relações entre vida e arte, performance e teatro.
\end{abstract}

Palavras-chave: Arte, Entrevista, Performance, Teatro, Vida.

\begin{abstract}
Dialogue caught between the director of the play Pulsão produced by Desvio Coletivo, and three guests to the Sala Preta Journal. The methodological approach of creation of this work served as the starting point for considerations about the nature and meaning of doing theater today, highlighting the relations between life and art, theater and performance.
\end{abstract}

Keywords: Art, Interview, Life, Performance, Theatre.

Beth Nespoli: Na primeira parte da Pulsão, um terço dos espectadores vive uma experiência de olhos vendados. Conduzido por um dos 18 médicos, o espectador que decide viver o papel de paciente, é tocado fisicamente, escuta textos nos ouvidos, e se desloca por diferentes espaços, vivendo diferentes situaçõessituaóes, manipulando objetos e materiais diversos. Depois disto, desvendado, cada espectador/paciente interage verbalmente em uma consulta médica. Enquanto isto, o resto do público assiste

\footnotetext{
1 Escola de Comunicações e Artes da Universidade de São Paulo (ECA - USP)

2 Instituto de Artes da Universidade Estadual Paulista (IA-UNESP)

3 Faculdade de Educação da Universidade de São Paulo (FEUSP-USP)

4 Escola de Comunicações e Artes da Universidade de São Paulo (ECA - USP)
} 
a cena que desejar, circulando pelo espaço em comum, podendo beber uma taça de vinho. Penso que de alguma forma essa imersão cinestésica remete o espectador/ paciente para outra percepção, catapulta-o para uma outra qualidade de vivência. Percebo um eixo norteador nesta modalidade de teatro relacional: tocar pelo corpo para desestabilizar a experiência como acúmulo. Buscar a experiência como corte radical, que desestabiliza o acúmulo.

Julio Groppa: Eu fiquei pensando, aqui, no jogo de palavras entre o "fabril" e o "febril", porque tem um lastro fabril disso que a gente poderia chamar dessa "grande clinicalização do mundo". Não é por acaso que isso surge como uma temática. Eu gosto da ideia de um internamento lá, em Pulsão. É um internamento que acontece, não é? Tanto para quem visita, quanto os próprios doentes. O próprio ato de viver se tornou alguma coisa que não é da ordem do acaso, da circunstância, mas do cuidado perene, científico, se podemos dizer isso. Então a gente tem uma dificuldade fabril em relação ao corpo. A nossa atitude contemporânea em relação ao corpo como instância da vida é uma atitude rigorosamente fabril. $\mathrm{E}$ aí esse internamento, paradoxalmente, transforma o fabril em febril. Eu acho que o que acontece lá é a potência do cair doente, porque me parece que a gente cai doente neste espetáculo. Mas é uma doença que remeteria a esse plano do farmacon, da palavra como farmacon. Desde a palavra sussurrada no ouvido dos espectadores que fazem o papel dos pacientes. Me parece que este é um enfrentamento em relação a essa palavra como "mais vida", mas que obrigatoriamente exigiria cair doente. Não espaço é a saúde aqui como alguma coisa que você trataria profilaticamente, mas senão no interior mesmo da própria luta com a doença. Aqui, a doença passa a ser a imanência. Estamos doentes, mas doentes no sentido dessa febre em direção, em vias de uma grande saúde, nos termos de Niezche, que dizia: "Dai-me febres!" Ele pedia a febre. A febre como condição de passagem, de transformação. Então o febril lá é uma conquista, pelo que eu posso entender. Este trabalho da arte como uma grande febre infligida ao outro. E se não houver essa febre, não tem conversa.

Beth Néspoli: E de repente eu me percebo com a pergunta: "Qual é a sua doença?". Ali, em Pulsão, naquela primeira parte, você se dá conta da doença que é a sua saúde. Quando estive como espectadora, eu me perguntei: “que corpo é esse?" Que doença que é essa saúde que me faz a cada cafezinho pensar: é açúcar, açúcar faz mal, a preocupação com a saúde, hoje, é uma doença. 
Julio Groppa: O colesterol, x, y, z (...) Nós estamos falando de alguma coisa - a doença - que é literal aqui. Não é metafórico. Cair doente aqui é uma condição dessa mais vida, dessa outra vida. Ou se você quiser imanência, nos termos deleuzianos - e eu acho que estamos falando o tempo (todo) disso aqui. Dessa imanência da vida, que não é aquilo que a gente tem exatamente, mas aquilo que nós estamos em vias de ter. Então essa "febrilização" me parece que é uma coisa muito interessante, que ela parte de uma experiência compartilhada por todos nós nesse grande internamento.

Carminda Mendes: Durante o tempo que eu estive ao lado do Marcos Bulhões no processos dos experimentos em performance, sempre me sentia como se eu estivesse entrando na peste do Artaud. Tanto é que eu entrei na peste.

Julio Groppa: A ideia da peste é boa também, talvez da febre à peste.

Carminda Mendes: Eu tenho uma relação afetiva com eles, o Desvio. Quando, no final de Pulsão, os corpos nus do coro passam e convidam a gente a criar imagens e a dançar, depois de todas as cenas hospitalares, meu corpo e mente já em febre, percebo que uma espécie de catarse se dá, pelo acontecimento sem rédeas, pelo coletivo que mistura atores e espectadores. Eu não sei se os espectadores vienciaram desta forma. Porque uma das potências que eu acho do trabalho de coralidade no grupo, e desde o início dos cursos eu percebi isto, é esse não rosto, esta coralidade que apaga as individualidades, o ego inflamado do artista. Percebo a cura ou a febre coletiva numa perspectiva de uma reinvenção. Nós criamos ali, naquele espaço gerado em Pulsão, sim, um internamento, mas é um internamento no qual você vai por um outro caminho, um internamento diferente, reinventado.

Julio Groppa: Acho que é um internamento filosófico. Esse que é o paradoxo que me parece bonito neste espetáculo, porque não se trata de negar isso, mas é de viver a clinicalização como alguma coisa que não é da ordem da medicina. Desse grande gesto, digamos assim, em torno dessa intensificação de um outro corpo. Não é o reparo de um corpo doente, mas é a produção de um corpo febril. Acho que é uma outra coisa. Que é o que acontece com a gente, com as paixões. A gente não cai doente? A paixão... é tudo febril. Quando a gente se defronta com um autor maraviIhoso, com uma peça maravilhosa. Eu não participei de Pulsão como paciente, mas como visita. Eu acho que daria pra nós separararmos isso. A vivencia da visita hospitalar. Aquele que vai visitar o doente e que fica percorrendo... Ele tem um papel interessante lá. Eu tive uma relação de pura fruição com aquilo. Eu gostei muito do trabalho, 
particularmente. Achei que é um trabalho absolutamente relevante porque é contemporâneo, de fato. Seja na forma, os artifícios aí, toda essa discussão da possibilidade teatral, a performance, mas fundamentalmente pelo que ele traz à baila, e que remete a alguma coisa que é antiga e absolutamente contemporânea, que tem a ver com esse internamento a céu aberto em que a gente vive. É um pacto do discurso da medicina sobre os nossos modos de vida. $E$ como que ele se endereça a isso. Como uma força que está no mundo, ele doma essa força e transforma essa força em outra coisa. Acho que ele retira o farmacon da medicina e o aproxima da filosofia por meio da arte. Se eu pudesse resumir o que foi pra mim a experiência lá, não é uma experiência curativa. Ela é adoentadora. Em geral, o campo artístico está muito ligado à figura autoral, que tem relação com a genialidade, com a criação de quem o fez. Penso que o que está em jogo em Pulsão é uma abordagem diferente: o espetáculo é uma releitura da experiência limite do adoecimento fisico de Marcos Bulhões, que é menos da ordem da genialidade criativa, mas a relaçãoda relacao com alguma coisa vivida. Nesse sentido, eu queria operar em torno da experiência como sendo catalisadora da potência narrativa. A experiência no sentido foucaultiano, menos como acúmulo, mas como aquilo que a gente deixou de ser. Então, eu queria saber aquilo que nos transforma de fato. Menos aquilo que eu aprendi e mais naquilo de eu desaprendi. Então, queria que o Marcos pudesse comentar um pouco sobre o papel da experiência corporal limite que ele teve durante a concepção do espetáculo.

Marcos Bulhões: Na primeira versão do roteiro, Pulsão, era uma performance autobiográfica. Depois, o projeto se transformou em uma proposição de uma experiência relacional, um ritual poético coletivo. $O$ roteiro passou a se estruturar em torno de jogos performativos onde os espectadores e atuadores tivessem condições de vivenciar ações que levantam questões que dizem respeito a qualquer pessoa em risco de vida. Em 2010, depois de quarenta dias internado em um hospital de infectologia, me informaram que eu não tinha diagnóstico e meu estado era terminal. ${ }^{5}$ Durante a madrugada seguinte a esta noticia, comecei a ter visões. Era uma mescla de memórias pessoais, memórias de cena, personagens que surgiam, amores, pessoas da minha família e artistas que eu tinha assistido no palco e que se materializavam ali, no quarto 509 do Instituto Emilio Ribas. Por exemplo, acordei uma noite sem respirar, e, colo-

5 Em agosto de 2010, Marcos Bulhões iniciou processo de infecção que se prolongou até outubro, quando foi internado. Quarenta dias depois, nao havia mais perspectiva de cura. A nova médica residente, Dra. Fernanda Matos, percebeu que havia um exame que não tinha sido feito, o da Leishmaniose e esta descoberta o salvou. 
cando a máscara de oxigênio, vislumbrei Pina Bausch dançando um fragamento da coreografia Café Müller, de braços estendidos, deslizando pela parede, batendo com a cabeça no vaso sanitário do banheiro. Em outra noite, vejo Chico Villa, ator potiguar com quem trabalhei muitos anos, que cantava uma música de cena saindo de dentro de um cesto de roupa suja. Acordava no meio da noite e via as paredes do quarto se transformando em telas, onde eram projetados espaços vividos em diferentes épocas. Então comecei a desenhar e escrever o primeiro roteiro: um artista está morrendo e escreve um roteiro. Começar a desenhar foi muito importante, porque até então eu estava vivendo um momento que era de natureza dramática, um momento de luta, de enfrentamento. Quando veio a notícia da ausência de diagnóstico, eu saí do estado dramático e entrei no estado trágico, uma certa imobilidade, um certo silêncio, uma ausência de sofrimento. Aqueles que já estiveram defronte com a morte conhecem este estado de suspensão. Naquele momento, pensei: já que não tenho saída, vou ocupar esse tempo fazendo meu último trabalho. Fiz um sumário com doze cenas e decidi resistir até a décima segunda cena terminar.

Júlio Gropa: Uma segunda questão para Marcos: se você pudesse perspectivar um pouco isso, o que você deixou de ser com essa experiência no hospital?

Marcos Bulhões: Creio que perdi a necessidade mais individualizada do trabalho teatral. No auge da decadência física, prometi a mim mesmo que se escapasse, iria tentar me transformar num coro de performers, um desvio coletivo. Nesta experiência de quase morte, eu perdi a cisão entre o professor e o artista, eu perdi uma certa visão conservadora da universidade. Naquele momento, eu estava me rendendo a essa sistemática acadêmica de produtividade Lattes que vai nos afastando da criaçãocriacão artística. Abandonei a perspectiva do Teatro como sendo a transmissão de narrativas, conceitos, elaboração de formas interessantes. O teatro como discurso artístico foi sendo substituído por dois desejos que movem o Desvio: ganhar a rua com a performance urbana -a primeira imagem da intervenção Cegos surge neste momento, e, por outro lado, a vontade de investigar formas de teatro relacional - na perspectiva de uma Arte Relacional (Nicolas Bourriaud). $O$ que me interessa agora é a qualidade das experiências, das relações, das invençõesrelaçoes, a invenção de rituais que conectem espectadores e artistas de forma não convencional. A criação de zonas autônomas temporárias de vida em potência.

Beth Néspoli: "Qual é a sua doença" era uma pergunta propulsora? O Flávio Desgranges fala no livro $A$ invenção da Olhadela que a cena contemporânea, hoje, 
é uma cena interrogativa, uma cena em que você não pergunta mais, o que isso quer dizer? Mas, sim, o que está acontecendo comigo? Eu me perguntei isso quando fui ver Pulsão. Eu me lembro que, quando entrei no palco, uma das pessoas estava deitada no chão, com pedrinhas sobre o corpo. Eu me perguntei: "que corpo é esse deste espectador?" Eu pensei que jamais me permitiria, que não teria coragem de me deitar ali no chão, de estar naquela entrega corporal com aquelas pessoas dentro de um palco. Para mim, a interrogação posta em cena - "Qual é a sua doença? ", realmente aconteceu, quando percebi minha própria limitação. Vocês no grupo têm respostas para esta pergunta? Vocês fizeram algo para que os espectadores pudessem buscar a respostas?

Marcos Bulhões: A dramaturgia é baseada em jogos performativos relacionais, que se contrapõem a algumas cenas construídas teatralmente, advindas do roteiro escrito no hospital. O jogo performativo é modo de criação, forma de manutenção do trabalho e também é espaço dramatúrgico aberto. Além dos solos, o jogo que chamamos de Consultório também foi gerado a partir da questão "qual é a sua doença?؛ Nesta cena, cada atuador desenvolveu uma série de perguntas a partir de uma base comum na qual as perguntas estão no limite entre uma pergunta clínica e uma pergunta de natureza existencial, por exemplo - "Como anda sua pressão? Ela está alta? De que forma você se pressiona?" Aqueles espectadores que vivem o papel de paciente podem escolher o seu nível de participação. Alguns destes espectadores decidem responder de uma forma intensa, colocando em cena questões de ordem mais pessoal e íntima. Outros respondem artificalmente, não artificialmente. Não pressionamos, nem impomos, nada. No final do acontecimento, revertemos esta posição através do jogo performativo que denominamos Identidade, no qual o ator se desnuda lentamente, enquanto expõe verbalmente os seus limites, palavras soltas sobre "o que Ihe aprisiona". "O que faz com que você não se mova?". O atuador tenta se colocar em risco, tenta abordar uma zona não que não é a de uma exibição narcisista, como acontece em certos depoimentos pessoais em cena. Tentamos transcender um diálogo formatado socialmente, encontrar um outro tipo de acesso, que pode incluir silêncios, toques, olhares prolongados, intimidade.

Julio Groppa: Percebo também um paradoxo, porque o espetáculo fala de um grande internamento. $\mathrm{O}$ evento, em si, é um internamento temporário, uma saída da vida real, uma suspensão do cotidiano, uma espécie de internamento. Eu estava pensando aqui naquela ideia da filosofia grega como fármaco. O filósofo tinha a função 
de cuidar da alma, como se tem um encontro aí entre a medicina e a filosofia na arte. Porque você está me falando de uma zona autônoma temporária que se abre e se fecha, mas dentro de um território muito delimitado. Existe neste caso um lastro clínico. Na verdade, ele é um grande internamento e o que podemos fazer com isso é o que gera alguma coisa de interesante. Transformar o internamento que era da ordem da morte para fazer a vida virar outra coisa.... eu queria apontar esse paradoxo. $\mathrm{Na}$ verdade, você está falando desde um lugar tomado pelas forças históricas.

Marcos Bulhões: Dispositivos de controle, do ponto de vista de Foucault.

Julio Groppa: Totalmente!

Beth Néspoli: Eu tenho uma curiosidade sobre as bases teóricas do trabalho, porque aqui nesta conversa, eu percebo a voz de Zé Celso Martinez Corrêa ressoando. E as bases teóricas do Zé Celso são Deleuze e o Guatarri, é o Nietzche, essa potência de vida. Eu penso, também, que é impossível, como você mesmo diz, separar o professor do artista, o acadêmico do criador. Eu vejo a teoria atravessando, uma teoria que se despe talvez dessa farmacon,desse "farmaco" sei lá, conceitual. Mas uma teoria que se despe desse academicismo enrijecido pra pulsar lá, você vê nítida a potência de poder lá, pulsando. Eu, por exemplo, às vezes eu me sinto muito adoentada pela teoria e não consigo que ela seja pulsante no meu trabalho, eu tenho essa dificuldade de lidar com ela.

Marcos Bulhões: A teoria atuou sempre, para nós, como um bisturi que ajudou a abrir perspectivas mais porosas, rizomáticas, de se pensar a vida e o fazer cênico. A teoria também nos ajudou a mudar a nossa relação anterior com o espectador, na tentativa de não cair no ranço pedagógico teatral. Mestres como Deleuze, Guatarri, Foucault, Nietzche, nos ajudaram a manter uma vigilância: Até que ponto estamos formatando pedagogicamente esta cena? Até que ponto essa cena está impondo uma mensagem? Como escapar da pretensão esclarecedora do aufklarung, do esclarecimento? Por isso, nos parece importante no final do ritual, nós desconstruímos desconstruir a atitude do coro médico. Senão, corremos o risco de mantermos uma postura cretina e arrogante, seja do artista que se considera "crítico", ou do artista que se nomeia "contemporâneo". Aqueles que, no fundo, sentem-se superiores aos espectadores, seja para esclarecê-los ideologicamente, seja para fornecer um produto cultural, cult, enigmático, a ser "consumido" por uma elite intelectual. Como escapar desse tipo de pedantismo? Essa compulsão pedagógica é inerente ao fazer teatral, é 
como um vício que temos de aprender a controlar. Costumo dizer que o espírito pedagogizante do padre José de Anchieta é um "encosto" que temos de exorcizar em sala de ensaio, continuamente. Além da teoria, e da proposta de um teatro ritual que estimule a potência de vida do público, defendida pelo mestre Zé Celso, foi fundamental a influência de artistas relacionais como Lygia Clark, Helio Oiticia e Ligia Pape.

Carminda Mendes: Durante a primeria fase do processo, para mantermos uma relação com o espectador do "não estamos querendo ensinar", nós faziamos muito essa discussão. Não queremos representar teatralmente o mundo, porque nós não sabemos nada. Nós queremos mais é perguntar. Desde os primeiros experimentos do Desvio, explorávamos esta dramaturgia em jogo. Esta é uma abordagem que também me interessa, o jogo performativo, não só como processo mas como estrutura dramatúrgica. Esta foi uma das nossas saídas, de pensar uma dramaturgia que não fosse narrativa, que não fosse representacional. Em Pulsão, o jogo performativo é uma estrutura aberta que permite que o atuador desenvolva as suas ações e, por outro lado, crie estruturas abertas ao diálogo com os espectadores.

Julio Groppa: Diferença pura então. Não igualdade, mas diferença pura. Fazer a diferença pra pulsar. Não é causar isonomia. Porque isso não existe. Constitucionalmente, plateia e atores estão separados pela diferença. É instaurar a diferença pura. É criar uma barreira entre eles, de não continuidade, que a representação tenta forjar, essa barreira de continuidade. Que o que eu estou dizendo aqui vai rebater lá no outro. Veja, o representacional também é performativo, mas é um performativo que a gente não quer. Porque ele também performa. Mas o representacional traz na narrativa, embutida, sempre uma lição de moral, em alguma medida. A questão aqui é assumir que nós não temos o que dizer para o outro. Assumir uma espécie de gagueira narrativa.

Beth Néspoli: Mas em compensação, a penúltima cena, ensaiada teatralmente, foi muito potente para mim. O protagonista, deitado na maca hospitalar, depara-se com o seu duplo pendurado por um gancho de metal que lhe rompe a carne enquanto surgem todos aqueles corpos desnudos se arrastando pelo chão. Esta imagem mexeu involuntariamente com a minha memória. Eu lembrei de uma cena de bíblia ilustrada do meu pai, foi muito forte. Às vezes, no debate sobre o teatro contemporâneo, a ação representacional surge como algo negativo, uma especie de "pecado" do qual nós temos que fugir de todas as maneiras. Eu discordo, penso que o representacional tem uma potênciapotencia dentro desse teatro performativo. Nas discussões da MIT, a Mostra 
Internacional de Teatro, recentemente, percebi que muitas vezes o representacional era um tido como um pecado mesmo. Um palavrão. E pude ver as pessoas reclamando do Romeu Castellucci: "o Castellucci no início me incomodou.... aquela coisinha dramática e aquela salinha", parecia que ele ia "pecando" pelo dramático. Era uma coisa tão forte de negação. Eu questiono este preconceito atual contra a cena representacional, teatral.

Julio Groppa: Gosto de descer a lenha no Teatro. E eu faço com a maior tranquilidade, porque eu faço isso com relação à Educação e com essas formas artísticas todas que tem a ver com essa aliança dessas narratividades, que a gente chamaria de culturais. O caso da Educação é exemplar nesse sentido, porque a Educação não é qualquer coisa, a gente fala em Educação como se ela fosse uma coisa secundária, na verdade ela é o grande mote que move o mundo. Mas eu estou falando desse laço pedagogizante que existe, sabe assim, na própria Medicina, no Direito, nas práticas artísticas e daí pra fora. Essas formas, aqui neste caso específico, teatrais que se aliam a uma certa normalização, a gente poderia chamar isso de Medicina Social também. Porque eles se colocam num mesmo plano dos médicos sociais que tomam para si a tarefa de reformatar o mundo, de que seria tarefa nossa elevar a racionalidade para os incautos.

Carminda Mendes: Inclusive o teatro "crítico", a cena "de esquerda", né? Nós discutíamos muito isso durante os experimentos em performance.

Julio Groppa: Sim, esquerda, direita e mais ou menos. Entre tudo o que está entre uma coisa e outra. A questão nossa com esses autores, primeiro tem a ver com essa ideia de que eles precisam nos empoderar para que nós possamos criar as nossas próprias coisas, porque eles não ensinam nada, afinal. A única coisa que eu aprendi convivendo com os autores - e eu convivo com um em específico já há bastante tempo, que no caso é o Foucault - é ser sozinho. A não tê-lo como Norte. Eu acho que o que muda nesses autores, nessa perspectiva pós-metafísica que a gente pode chamar pós-estruturalista, pós-crítica, pós-sei-lá-o-que, por falta de outro nome, é uma espécie de solidão, de abandono. E de uma responsabilização total daquilo que diz. Então, a responsabilidade é tua. Toma que o filho é teu. Se você resolveu por esse no mundo, você precisa dar conta do mundo que ele implica. É que, muitas vezes, essa narratividade teatral está muito lastreada por uma expectativa messiânica e profilática socialmente, de corrigir destinos e de dizer pras pessoas como é melhor viver. Eu não sei se é isso que está lá em Pulsão. Talvez tenha alguma coisa dessa natureza lá também. Porque a gente tá no tempo. Então não dá pra imaginar que a gente é extemporâneo. Nós estamos num tempo e a gente não sabe o 
que a gente tá falando aqui agora, que daqui a cinquenta anos vão rir de nós. Falar assim: nossa, eles achavam isso mesmo? Eles eram arrogantes o bastante pra achar que eles faziam isso impunemente? Vão rir de nós. Mas enquanto não chegar a isso, nós não vamos estar aqui pra ver, eu acho que cabe a gente talvez ter uma atitude, eu não chamaria de humildade, mas uma atitude não fascista. Isso é um dos títulos do prefácio que o Foucault faz ao livro do Deleuze e Guatarri, o Anti-Édipo. Porque a questão fundamental era como não ser fascista. Porque o fascismo está em todos os lugares. Quando o fascismo se alia à arte, aí nós temos uma hecatombe. Porque a arte sempre se coloca nesse lugar fora do tempo. Sendo fascista, invisibiliza muito esses jogos de poder que estão no gesto artístico. Então, isso de fato é um perigo que a gente corre, imenso. De achar que de fato a gente tem alguma espécie de missão em relação ao mundo. Acho que se a gente tem uma missão é por o mundo de cabeça pra baixo, é estragar a festa. Estragar as festas discursivas. Que pra mim, eu entendo que é este o trabalho da crítica.

Beth Néspoli: Penso que é estragar a festa com festa! Estragar a festa discursiva, quer dizer, essa festa arrogante, essa festa que é seríssima.

Carminda Mendes: Demorou pra nós aprendermos isso....

Julio Groppa: É que nós somos herdeiros de uma narratividade doutrinária, das ciências humanas.

Beth Néspoli: Eu acho que eu estou em outra etapa. Eu não consigo ter mais o discurso do "como não me submeter a ele". Fazemos parte do discurso, desde cima. Como escapar dele? Como ter coragem de criar alguma coisa?

Julio Groppa: Existe uma afirmação do Foucault que acho interessante: não tem como a gente não se submeter. Em alguma medida a gente vai se submeter. Mas estamos no tempo, e aí tem uma imagem que eu adoro, do Paul Veyne, historiador de Roma que foi um dos melhores amigos do Foucault. Ele propõe uma imagem que é o aquário dos tempos. Nós somos todos peixinhos nadando, dando voltas, pra lá e pra cá. E cegos, porque quem está no aquário do tempo não consegue ver o que é o seu próprio presente. Por isso que a gente só pode ver o que somos nos afastando daquilo que somos, guardando essa distância. E aí eu quero crer que a arte cria borbulhas, pequenas borbulhas. $\mathrm{O}$ que eu acho interessante são essas pequenas borbulhas no tempo. Nós estamos encerrados pelas águas do tempo e elas são os discursos, nós. Nós pensamos só aquilo que é possível a gente pensar. Não se trata de imaginar que nós não seremos governados. Nós seremos e somos governados. Mas a pergunta é: qual 
é o preço? Acho que a gente têm condições de responder. Eu não quero a este preço. Posso ser governado de outras maneiras. Então estamos nessas águas turvas, porque pra quem vive o presente, as águas são sempre turvas e gélidas. Nós não vivemos o presente. O presente é alguma coisa que nos sufoca porque nos impede de trafegar no próprio tempo, nos encerra. Presente é cruel nesse sentido. Esse afastamento do tempo é que é o trabalho infinitezimalmente crítico. De desacomodação do próprio tempo. Ou seja, a gente não pode nunca estar contente com o próprio presente. O presente é o nosso carrasco. Mas a gente pode fazer borbulhar, a gente pode reclamar. Essas bolhas no interior do tempo. Essas borbulhas que saem de nós como sendo uma forma de recusa. Quer dizer, até aqui tudo bem. Até aqui nós vamos, mas daqui em diante não. É fazer a manada parar. Por a mão na frente e a manada pára. Essa atitude, que eu acho que é uma atitude radicalmente crítica, que todos aqueles que estão envolvidos com o ser humano precisam ter. Daí vai da Arte à Medicina. Da Educação à Filosofia, ao Jornalismo. A tudo aquilo que tem a ver com os outros. Os narradores do próprio tempo, vamos dizer assim. Esses narradores do próprio tempo podem produzir essas borbulhas. E eu acho que essas borbulhas têm a ver com o trabalho da arte. Não só, não exclusivamente, porque também nós temos essa ideia de chamar de Arte tudo aquilo que é contra o poder. Isso não existe. A Arte é filha do poder da mesma maneira. Não existe esse estado de exceção que certos artistas criam. Esse estado de exceção, vamos dizer assim, essas borbulhas no tempo, isso não é privilégio da arte. Isso é privilégio de quaisquer outras práticas. Inclusive nas relações amorosas, familiares. Tudo pode criar esse "até aqui não". É a gente virar a mesa em alguma medida, mas a mesa desvira rapidamente. Eu não tenho a ilusão de que a gente tá criando um espaço infinito de liberdade, pelo contrário. Nosso espaço de liberdade é fundamentalmente crítico e muito momentâneo. Porque logo em seguida ele vai ser repurificado pela ordem.

Marcos Bulhões: Não pretendemos estar fora do tempo, nem isentos do sistema de controle. Não somos ingênuos. Mas é preciso resistir, forçar, tensionar, abrir brechas no muro cinzento do nihilismo, da acomodação com as estruturas. Para nós do Desvio, é fundamental manter a meta de promover ilhas de desordem no mar gelado do capitalismo tardio, como dizia Heiner Müller. Tentar criar bolhas de vida intensa no aquário escuro desta sociedade de consumo, cada vez mais conservadora.

Recebido em 17/03/2014 Aprovado em 30/04/2014 Publicado em 25/06/2014 